Bekkers, M.J.T.M., Knippenberg, F.C.E. van, Dulmen, A.M. van, Borne, H.W. van den, Berge Henegouwen, G.P. van. Survival and psychosocial adjustment to stoma surgery and nonstom bowel resection: a 4-year follow-up. Journal of Psychosomatic Research: 1997, 42(3), 235-244

\begin{tabular}{|l|l|}
\hline $\begin{array}{l}\text { Postprint } \\
\text { Version }\end{array}$ & 1.0 \\
\hline Journal website & $\underline{\text { http://www.jpsychores.com/article/S0022-3999\%2896\%2900288-7/abstract }}$ \\
\hline Pubmed link & $\underline{\text { http://www.ncbi.nlm.nih.gov/pubmed/9130180 }}$ \\
\hline DOI & $10.1016 /$ S0022-3999(96)00288-7 \\
\hline
\end{tabular}

This is a NIVEL certified Post Print, more info at http://www.nivel.eu

\title{
SURVIVAL AND PSYCHOSOCIAL ADJUSTMENT TO STOMA SURGERY AND NONSTOMA BOWEL RESECTION: A 4-YEAR FOLLOW-UP
}

\author{
M. J. T. M. BEKKERS, * F. C. E. VAN KNIPPENBERGa, A. M. VAN DULMEN,* H. W. \\ VAY DEY BORNE ${ }^{\circ}$ AND G. P. VAN BERGE HENEGOUWEN^ \\ * The Netherlands Institute of Primary Health Care, NIVEL, Utrecht, The Netherlands. \\ ${ }^{a} C P W O$ Institute, Klundert, The Netherlands. \\ 'Department of Health Education, University of Limburg, Maastricht, The Netherlands. \\ Department of Gastroenterology, University Hospital Utrecht, The Netherlands. \\ Address correspondence to: Dr. M. J. T. M. Bekkers, Netherlands Institute of Primary Health \\ Care, PO Box 1568, 3500 BN Utrecht, The Netherlands. Tel: 31302319946: Fax: \\ 31302319290: E-mail: M.BEKKERS@N1VEL.NL
}

\begin{abstract}
A prospective 4-year follow-up study was conducted to compare the psychosocial adjustment process and survival rate of 59 stoma patients with 64 bowel-resected nonstoma patients. Adjustment was assessed at 4 months, 1 year, and 4 years after surgery by the Psychosocial Adjustment to Illness Scale, a selfreport questionnaire (PAIS-SR). Analyses of covariance demonstrated that both subgroups experienced the same level of psychosocial problems 4 years after surgery. Interestingly, patients with poor early adjustment scores (4 months after surgery) were at significantly higher risk of dropping out because of death and terminal status during the follow-up period ( 1 and 4 years postoperatively). The presence of a stoma did not influence the risk rate for dropping out. These results demonstrate the need for prolonged psychosocial guidance of outpatients who have been surgically treated for colorectal canccr or inflammatory bowel disease.
\end{abstract}

\section{INTRODUCTION}

Stoma surgery is a procedure in which part of an affected bowel is removed and a passage is constructed through the abdominal wall. The passage is formed out of the remaining, healthy part of the bowel. The number of patients with a stoma in the Dutch population has been estimated to be about 17,000--a prevalence rate of about 115 patients per 100,000 inhabitants [1]. This number includes patients with an ileostomy, a stoma on the small intestine, and patients with a colostomy, a stoma on the large intestine. The most frequent 
indications for bowel surgery in general and stoma surgery in particular are colorectal cancer and inflammatory bowel disease (Crohn's disease and ulcerative colitis). In all cases, the preferred procedure is a nonstoma bowel resection; in a relatively small number of cases, however, stoma surgery cannot be avoided.

Stoma surgery is an intrusive operation with great impact on daily life and patient coping capabilities. The patient has to cope with a severe operation, loss of an important body function, a distortion of body image, and a change in physical functioning and personal care [2]. These changes in personal and physical circumstances require adaptation in every major life domain. Insight into the course of the psychosocial adjustment process following stoma surgery may help to clarify its determinants.

Investigations into the psychosocial consequences of stoma surgery can be divided into two broad categories [2]: (1) retrospective studies into long-term adjustment, that is, more than 1 year postoperatively [3-5]; and (2) longitudinal follow-up studies into short-term adjustment, that is, up to 1 year after surgery [1, 6-14]. Retrospective studies show that, in most patients, stoma surgery does not give rise to long-term adjustment problems. However, most of these retrospective studies lack adequate patient control groups. Without a control group of nonstoma bowel resection patients it is impossible to separate the general reactions of distress to the disease and treatment from the specific consequences of stoma surgery. Furthermore, retrospective designs are likely to give a distorted and incomplete picture of the actual situation. It is not possible to adjust for the effects of preoperative psychological status. Some studies [15-18] in which stoma patients have been compared with nonstoma patients have demonstrated a relative superior quality of life for resected nonstoma patients.

The latter group was found to be less depressed, experienced fewer changes in body image, and had higher rates of work resumption.

Prospective longitudinal studies, on the other hand, have been concentrated on short-term adjustment. The studies reported a significant increase in emotional problems such as anxiety, depression, anger, and irritation in about $18 \%$ to $25 \%$ of patients 1 year after stoma surgery. The stoma has been a factor in restricting social and sexual life in about the same number of patients. To what extent stoma surgery itself is responsible for the reported psychosocial problems cannot be concluded, because none of the studies had included a control group. Furthermore, until now, it has remained unclear in what way these problems develop in the long run.

Adequate longitudinal follow-up studies into long-term adjustment are needed to validate the results of previous retrospective investigations. In addition, this type of study provides the opportunity to investigate another challenging issue: the relationship between psychosocial adjustment and survival rate. There are some indications that poor psychosocial adjustment to stoma surgery is associated with a higher death risk. Wade [11] found 25\% of the colostomy patients who were anxious or depressed at ten weeks after surgery were among those who died during the following year, whereas "only" $13 \%$ of the low anxiety/depression stoma patients died during this period. This finding should be interpreted with caution because no comparison was made with nonstoma patients and because it related to a relatively short period of time.

A few years ago, we completed a longitudinal control group study (study I) into psychosocial problems 1 year after major bowel surgery [1, 2, 14]. Three main conclusions could be inferred from that study. First, compared to nonstoma bowel resection, stoma surgery appears to cause significantly more psychosocial problems, in particular with respect to sexuality and work during the first 4 postoperative months. One year after surgery these differences could not be demonstrated again. Second, suffering from malignancy did not lead to additional psychosocial problems. Third, the degree of adaptational problems is mainly associated with psychological characteristics of the stoma patient; that is, feelings of selfefficacy concerning social functioning and perceived ability handling the stoma. These 
Bekkers, M.J.T.M., Knippenberg, F.C.E. van, Dulmen, A.M. van, Borne, H.W. van den, Berge Henegouwen, G.P. van. Survival and psychosocial adjustment to stoma surgery and nonstom

characteristics were assessed shortly after surgery. Stronger feelings of self-efficacy predicted more favorable outcome 1.

For the purpose of the present study (study If), participants of study I who survived 4 years were again asked to cooperate. The objective of the study was twofold: (l) to describe the 4year follow-up of psychosocial adjustment to stoma surgery and nonstoma bowel resection; and (2) to compare the short-term adjustment process of long-term participants--patients who have completed both studies -- with that of patients who have dropped out for reasons of death or terminal status. In addition to the psychosocial information derived from these subgroups, the study will give more insight into the further course of disease of patients with chronic bowel diseases (i.e., colorectal cancer, Crohn's disease and ulcerative colitis). Finally, the results may be important to understand the need for long-term psychosocial guidance of these patients.

\section{METHOD}

\section{Subjects}

In study I, data were gathered at three assessment points: 1 week (T1); 4 months (T2): and 1 year (T3) after bowel surgery. At the end of this first study, 99 patients. 46 stoma patients, and 53 nonstoma patients, out of 123 patients at the start, were still participating. In the present study (study II) (4 years after surgery, i.e., T4), these same 99 patients were asked to take part once more: 68 appeared to be willing and able to participate once again (Table 1).

\section{[TABLE 1]}

Of these 68 participants (i.e., 55\% of 123 patients at the start of study 1), 9 had had a colostomv for treatment of colorectal cancer, 19 had had an ileostomy for treatment of a benign disease (Crohn's disease or ulcerative colitis), 24 patients had undergone nonstoma bowel resection because of a colorectal tumor, and 16 patients underwent nonstoma bowel resection mainly because of Crohn's disease. The total sample consisted of 26 men and 42 women, mean age 47 years (sd 18.9). As in the first study, the four patient subgroups differed in gender $\mathrm{X} 2=8.8, d f=3, \mathrm{p}=0.03)$, age $\left(\mathrm{F}=22.0, d J \sim 3,64, \mathrm{p}^{\sim<0.001}\right)$, and income $(\mathrm{F}=5.9, d J-3,64, \mathrm{p}<\sim 0.001)$ distribution. Outcome scores were adjusted for these differences.

\section{[TABLE 2]}

\section{Dropouts}

A total of 55 patients had dropped out between hospital discharge and 4 years postsurgery. The main reasons were refusal $(n=20)$, death $(n=14)$, and terminal status $(n=10)$. In particular, the number of stoma patients treated for cancer had decreased dramatically since surgery, mainly because of death or terminal status (Table ll).

The sociodemographic profiles of the 24 patients 2 who dropped out for reasons of death or terminal status were compared to those of the 68 long-term participants. These subgroups differed in gender $(\mathrm{X} 2=9.6, d f=1, \mathrm{p}=0.002)$ and age $(\mathrm{F}=6.5, d f=1,90, \mathrm{p}=0.01)$ distribution. The male:female ratio was 18:6 in the dropout group and 26:42 in the participant group. Mean age of the dropouts was 58 years ( $\mathrm{sd}=12.3)$, and that of the participants was 47 years (sd=18.9). Outcome scores will be adjusted for these differences.

\footnotetext{
${ }^{1}$ A manuscript on the relationship between short-term self-efficacy and long-term psychosocial adjustment is currently in preparation.

${ }^{2}$ The total number of patients who had dropped out between hospital discharge and T4 for reasons of death or end-stage disease. Sociodemographic characteristics and PAIS-SR scores of both subgroups did not differ.
} 
Bekkers, M.J.T.M., Knippenberg, F.C.E. van, Dulmen, A.M. van, Borne, H.W. van den, Berge Henegouwen, G.P. van. Survival and psychosocial adjustment to stoma surgery and nonstom bowel resection: a 4-year follow-up. Journal of Psychosomatic Research: 1997, 42(3), 235-244

The sociodemographic characteristics of the 20 patients who refused to participate (at T2, T3, or T4) did not differ from the sociodemographic data of the long-term participants (Table III).

\section{[TABLE 3]}

\section{Psychosocial assessment}

Within the framework of the first study, psychosocial adjustment was measured twice (at T2 and T3) by means of the PAIS-SR [19]. At T4 the PAIS-SR was used again.

The Dutch version of the PAIS-SR [1] consists of five subscales3: (1) vocational environment, six items, for example, concerning vocational impairment, time lost on job, and vocational goals; (2) domestic environment, eight items, for example, concerning domestic impairment, family communication, and financial resources; (3) sexual relationship, six items, for example, concerning sexual interest, sexual satisfaction, and sexual dysfunction; (4) social environment, six items, for example, concerning individual and family leisure interest and activity; and (5) psychological distress, seven items, for example, concerning anxiety, depression, and self-devaluation. The PAIS-SR provides an overall index by summing all 33 item scores and generates indexes for the five domains. High scores refer to poor psychosocial adjustment. The indexes (Cronbach's alpha) for internal consistency for these scales were satisfactory to good, varying from 0.76 to 0.91 in study I and 0.71 to 0.87 in the present study.

Medical parameters studied were diagnosis and course of disease (i.e., relapse yes/no, terminal status); sociodemographic variables included gender, age, marital status, income, and education (all one-item variables).

\section{Statistical procedure}

Data were analyzed by means of the covariance procedure. The PAIS-SR total score, on the one hand. and the scores on the five PAIS-SR subscales, on the other hand, were subsequently treated as dependent variables in two separate series of analyses. Type of treatment (stoma vs. nonstoma), diagnosis (cancer vs. benign disease), and status of participation (long-term participation vs. dropout based on death/terminal status) were treated as independent variables. As previously indicated, the four patient subgroups differed on a number of sociodemographic variables. Two of these variables, age and income, served as covariates. Gender was treated as an independent variable in separate covariance procedures, but showed no significant differences. For this reason, gender was not included in the final analysis of covariance.

\section{RESULTS}

\section{PSYCHOSOCIAL ADJUSTMENT TYPE OF TREATMENT AND DIAGNOSIS}

In this section, differences in long-term (T4) psychosocial adjustment of stoma and nonstoma patients are described. Analysis of covariance demonstrated that, in general, both subgroups experienced the same level of psychosocial problems 4 years after surgery.

Similarly, there appeared to be no differences between both diagnostic groups. There was no interaction effect of treatment and diagnosis (Table IV).

One of the covariates, income, however, appeared to have a significant effect on the PAISSR total score. Further analyses showed that income was negatively correlated with the overall adjustment score of patients (Pearson's $r=0.26$, $\mathrm{p}=(\mathrm{I} .() 2)$ : higher income was associated with a better adjustment process.

\footnotetext{
3 The original English version consists of seven subscales. In study I, two scales were omitted because of low internal consistency (for a complete description, see Bekkers [1].
} 
Bekkers, M.J.T.M., Knippenberg, F.C.E. van, Dulmen, A.M. van, Borne, H.W. van den, Berge Henegouwen, G.P. van. Survival and psychosocial adjustment to stoma surgery and nonstom

Multiple analyses of covariance demonstrated no significant impact of treatment and/or diagnosis on the five major life domains as well.

\section{[TABLE 4]}

\section{Psychosocial adjustment: status of participation}

The early (T2 and T3) PAIS-SR total scores of the long-term participants ( $\mathrm{n}=68)$ were compared to those of the patients who dropped out for reasons of death and terminal status later on. Patients who dropped out because of death or terminal status between 4 months following surgery (i.e., after measurement T2) and 4 years following surgery $(n=20)$ had poorer overall adjustment scores at $\mathrm{T} 2$ than the longterm participants at the same timepoint $(\mathrm{F}=8.54$, d./'=1, $\mathrm{p}=0.004)$. Multiple analyses of covariance showed significant differences in regard to work, sexuality, and psychological distress in particular.

Likewise, analysis of covariance revealed that the patients who dropped out for the same reasons between 1 year following surgery (i.e., after measurement T3) and 4 years following surgery $(n=13)$ had experienced more psychosocial problems on T3 than the long-term participants $(\mathrm{F}=3.83$, dr=l, $\mathrm{p}=0.05)$. Figure 1 displays the adjusted means on the PAIS-SR total scale at T2 and T3 for long-term participants and the patients who dropped out because of death or terminal status. The means and levels of significance are based on the analyses of covariances presented previously.

Again, a series of covariande procedures was performed to elucidate the adjustment scores of long-term participants $(n=68)$ versus the scores of the patients who refused to participate at T3 or T4 $(n=20)$. Neither at T2 nor at T3 did the overall adjustment scores between these subgroups show any differences.

\section{[FIGURE 1]}

\section{Psychosocial adjustment." type of treatment vs. status of participation}

To investigate the effect of type of treatment (stoma vs. nonstoma) on the PAISSR scores, the same series of analyses described in the previous paragraph were repeated. No main effects of the type of treatment variable were found in either of the analyses, but a two-way interaction was demonstrated between type of treatment and status of participation (longterm participants [ $n=68]$ vs. early death/terminal status since T2 In=20]; Table V). The combined adjusted means pointed out that the early PAIS-SR total scores of stoma patients who died or became terminally ill later on were significantly less favorable than the adjustment scores of the nonstoma patients who later dropped out for the same reasons.

Post hoc cross-tabulation was performed to further identify the specific patients at risk here. These analyses revealed that colostomy cancer patients run a substantially greater risk of dropping out than all other subgroups (Table VI). In addition, PAIS-SR scores at T2, adjusted for age and income, were assessed. The mean PAISSR score of the dropouts among stoma cancer patients was the highest, indicating more psychosocial problems.

\section{[TABLE 5] AND [TABLE 6]}

\section{DISCUSSION}

As far as we know, this study is the first longitudinal prospective investigation into the long-term psychosocial problems after major bowel surgery. Until now it has been unclear as to what extent psychosocial functioning was influenced by stoma surgery. Results indicate that stoma patients do not encounter more problems in daily life than nonstoma bowelresected patients 4 years after surgery. This finding is consistent with most previous retrospective studies [3-5] into long-term adjustment. 
The data were consistent with the adaptation process as observed in the first investigation $[1,13]$ on the same patient group. The first investigation showed that, at first, stoma patients experienced significant problems, in particular, with respect to sexuality and work. In the course of the first postoperative year, however, these problems diminished. At l year postoperatively, the stoma was no longer causing additional psychosocial difficulties. This pattern was no different in the present study, indicating that stoma patients are still able to cope effectively with the presence of the stoma.

Very interestingly, in this study, poor early psychosocial adjustment scores, as measured by the PAIS-SR, appeared to predict death and terminal status later on. Possible effects of age or other demographic variables were accounted for. Wade [11] reported similar findings: anxiety and depression were associated with higher death risk.

Apart from death and terminal status a substantial proportion of patients in our study dropped out because they were no longer willing to participate. Additional analyses showed that the early adjustment process did not predict one's tendency to refuse. In other words, poor early adjustment scores discriminated between the various reasons for dropout later on.

The question now is whether there is a causal relationship between unfavorable adjustment scores and higher death risk later on. Our study showed that stoma cancer patients in particular run a higher risk of dropping out than the other patients. At the same time, the stoma cancer patients reported the poorest early adjustment scores. To some extent, these findings are related to the nature of the disease. In contrast, with inflammatory bowel disease, colorectal cancer is a more life-threatening disease, in turn influencing the patient's psychosocial functioning. Furthermore, colostomy is mainly performed in cases of rectal cancer and the mortality rate from rectal cancer is known to be relatively high [20]. Yet, the results cannot be explained sufficiently on the basis of these facts alone.

First, patients who were seriously ill (relapse, complications) at the time of the early adjustment assessments were excluded from the analyses presented here. In other words, PAIS-SR data were not influenced by health status: all patients measured were equally healthy. Second, it is unclear why the early adaptation scores of the other cancer patients--in particular nonstoma cancer patients who dropped out-- were far more favorable than those of stoma cancer patients who dropped out. Furthermore, the adaptation scores of the other cancer patients did not differ from the noncancer patients.

Presumably, high dropout and the poor adjustment scores preceding dropout of stoma cancer patients seem, at least to some extent, to be influenced by psychological factors. The colostomy patients face a double threat. ()n the one hand, they suffer from a life-threatening disease and, on the other hand, they face the mutilating and functional consequences of the stoma. Some patients may not be able to cope effectively with both threats at the same time, leading to a cumulative debilitating effect on psychological and social well-being and, in turn. on patients" physical condition. In study I $[1,13]$ it was shown that psychosocial adjustment is mediated by self-efficacy expectations: stronger feelings of personal competence with respect 10 daily functioning (as measured shortly after surgery) were associated with fewer psychosocial problems postoperatively. The relationship between adjustment and self-efficacy on the one side and dropout for reasons of death or terminal status on the other side is currently the subject of further investigation.

The outcome implies that guidance of bowel-resected patients should not slack off after hospital discharge but should be sustained for an extended period of time. Based oll the results of this study, attention should be focused on problems related to work and sexuality and on psychological distress. Psychosocial guidance should be offered to patients at risk by a trained stoma nurse, social worker, or psychologist.

Finally, we comment on the design of this study and its measuring instruments. Poor early PAIS-SR scores were shown to predict nonsurvival later on. However, as the number of dropouts for reasons of death or terminal status was relatively small, this conclusion should be interpreted with caution. More research into this subject with larger numbers of patients included are necessary to further validate the results. In addition, future research should take, 
Bekkers, M.J.T.M., Knippenberg, F.C.E. van, Dulmen, A.M. van, Borne, H.W. van den, Berge Henegouwen, G.P. van. Survival and psychosocial adjustment to stoma surgery and nonstom bowel resection: a 4-year follow-up. Journal of Psychosomatic Research: 1997, 42(3), 235-244

beside relapse and complications, more medical factors into account (e.g., stage of disease, surgical technique and results, and extension of bowel resection).

The Dutch version of the PAIS-SR appeared to be a valid and reliable instrument for assessing the psychosocial adjustment process to bowel surgery [1]. Now, the instrument should be applied to other groups of patients, in this way, more information would be obtained about the relative seriousness of the symptoms. The present form of the PAIS-SR refers mainly to functional limitations of disease and treatment related to work, sexuality, and social life. Only one of the five subscales relates to psychological well-being (Psychological Distress subscale) and none to the positive effects. In future research it would be highly recommendable to assess a weighted adaptation score. For this purpose, the importance of each subscale should be assessed by asking the patient to attach a personal value to each life domain.

Acknowlegdements--This follow-up study was made possible by the financial cosupport of ConvaTecSquibb BV. The Netherlands.

\section{REFERENCES}

1. Bekkers MJTM. Psychosociale aanpassing na aanleg van een darmstoma: een gekontroleerde studie [Psychosocial adaptation to stoma surgery: a controlled study.] PhD thesis, Universiteit Utrecht Utrecht, The Netherlands 1993.

2. Bekkers MJTM, van Knippenberg FCE, van den Borne HW, et al. Psychosocial adaptation to stoma surgery: a review. J Behav Med 1995;18:1-31.

3. McLeod RS, Lavery IC, Leatherman JR, et al. Factors affecting quality of life with a conventional ileostomy. World J Surg 1986;10:474-480.

4. Keltikangas-J irvinen L, J irvinen HJ. Psychosocial adaptation to ileostomy: a study after construction of conventional and continent stomies. Scand J Gastroenterol 1987;22:202206.

5. K/Shler LW, Pemberton JH, Zinsmeister AR, et al. Quality of life after proctocolectomy. A comparison of Brooke ileostomy, Kock-pouch and ileal pouch-anal anastomosis.

Gastroenterology 1991;101:679-684.

6. Thomas C, Madden F, Jehu D. Psychosocial morbidity in the first three months following stoma surgery. J Psychosom Res 1984;28:251-257.

7. Thomas C, Madden F, Jehu D. Psychological effects of stomas--1 psychosocial morbidity one year after surgery. J Psychosom Res 1987;31:311-316.

8. Thomas C, Madden F, Jehu D. Psychological effects of stomas--II. Factors influencing outcome. J Psychosom Res 1987;31:317-322.

9. Thomas C, Turner P, Madden F. Coping and outcome of stoma surgery. J Psychosom Res 1988;32:457-467.

10. Oberst MT, Scott DW. Postdischarge distress in surgically treated cancer patients and their spouses. Res Nurs Health 1988;11:223-233.

11. Wade BE. Colostomy patients: psychological adjustment at 10 weeks and 1 year after surgery in districts which employed stoma-care nurses and districts which did not. J Adv Nurs 1990;15:1297-1304.

12. McLeod RS, Churchill DN, Lock AM, et al. Quality of life of patients with ulcerative colitis preoperatively and postoperatively. Gastroenterology 1991; 101:1307-1313.

13. Bekkers MJTM, van Knippenberg FCE, van den Borne HW, et al. Het verloop van de psychosociale aanpassing na stoma-aanleg [The psychosocial adaptation process following stoma surgery]. Gedrag \& Gezondheid 1994,22:186-197.

14. Bekkers MJTM, van Knippenberg FCE, van den Borne HW, et al. Prospective evaluation of psychosocial adaptation to stoma surgery: the role of self-efficacy. Psychosom Med 1996;58:183-191.

15. Williams NS, Johnston $\mathrm{D}$. The quality of life after rectal excision for low rectal cancer. $\mathrm{Br}$ J Surg 1983;70:46(P462.

16. MacDonald LD, Anderson HR. Stigma in patients with rectal cancer: a community study. J Epidemiol Commun Health 1984;38:284-290. 
Bekkers, M.J.T.M., Knippenberg, F.C.E. van, Dulmen, A.M. van, Borne, H.W. van den, Berge Henegouwen, G.P. van. Survival and psychosocial adjustment to stoma surgery and nonstom bowel resection: a 4-year follow-up. Journal of Psychosomatic Research: 1997, 42(3), 235-244

17. MacDonald LD, Anderson HR. The health of rectal cancer patients in the community. Eur J Surg Oncol 1985;11:235-241.

18. Wyke R J, Edwards FC, Allan RN. Employment problems and prospects for patients with inflammatory bowel disease. Gut 1988;29:1229-1235.

19. Derogatis LR. The psychosocial adjustment to illness scale (PAIS). J Psychosom Res 1986;30:77-91.

20. Statistics Netherlands, Ministry of Health, Welfare and Sports. Vademecum of health statistics of The Netherlands, Voorburg, Heerlen, Rijswijk 1995.

\section{TABLES AND FIGURES}

Table 1.-Number of participants at T1 (at the beginning of study I during hospital admission), T2 (4 months postoperatively). T3 (1 year after surgery), and T4 (study II, 4 years after surgery)

\begin{tabular}{lcccc}
\hline & $\mathrm{T} 1$ & $\mathrm{~T} 2$ & $\mathrm{~T} 3$ & $\mathrm{~T} 4$ \\
\hline Stoma (malignant) & 26 & 25 & 20 & 9 \\
Stoma (benign) & 33 & $2 \%$ & 26 & $(34.6 \%)$ \\
19 \\
Nonstoma (malignant) & 39 & 34 & 31 & $(57.6 \%)$ \\
24 \\
Nonstoma (benign) & 25 & 24 & 22 & $(61.5 \%)$ \\
16 \\
Total & 123 & 111 & 99 & $(64.6 \%)$ \\
& $(100 \%)$ & $(90.2 \%)$ & $(50.4 \%)$ & $(55.3 \%)$ \\
\hline
\end{tabular}

"Numbers in parentheses: percentage of participants based on the total paticnt subgroup at the start of study $\mathbf{I}$.

Table II.-Reasons for dropout in first 4 years after surgery

\begin{tabular}{lccccc}
\hline & $\begin{array}{c}\text { Stoma } \\
\text { (malignant) }\end{array}$ & $\begin{array}{c}\text { Stoma } \\
\text { (benign) }\end{array}$ & $\begin{array}{c}\text { Nonstoma } \\
\text { (malignant) }\end{array}$ & $\begin{array}{c}\text { Nonstoma } \\
\text { (benign) }\end{array}$ & Total $^{\text {a }}$ \\
\hline Refusal & 4 & 6 & 5 & 5 & 20 \\
Death & 8 & 2 & 4 & - & $\left.\begin{array}{c}(16.3 \%) \\
14 \\
(11.4 \%) \\
10\end{array}\right)$ \\
Terminal status & 5 & 1 & 4 & - & $4.1 \%)$ \\
Stoma surgery & NA & NA & 2 & NA & $\begin{array}{c}(4.6 \%) \\
5 \\
(4.1 \%) \\
55\end{array}$ \\
Stoma reversed & - & 5 & NA & 9 & $(44.7 \%)$ \\
Total & 17 & 14 & 15 & & 9 \\
\hline
\end{tabular}

"Numbers in parentheses: dropout percentage based on the total number of participants at the start of study $\mathrm{I}$. 
Bekkers, M.J.T.M., Knippenberg, F.C.E. van, Dulmen, A.M. van, Borne, H.W. van den, Berge Henegouwen, G.P. van. Survival and psychosocial adjustment to stoma surgery and nonstoma bowel resection: a 4-year follow-up. Journal of Psychosomatic Research: 1997, 42(3), 235-244

Table IIl.-Sociodemographic characteristics of participants at T4 $(N=68)$ vs. nonresponders $(N=20)$

\begin{tabular}{|c|c|c|c|c|c|}
\hline & Participants & Nonrespondents & Value & $d f$ & $\begin{array}{l}\text { Level of } \\
\text { signiticance }\end{array}$ \\
\hline Gender & $\begin{array}{r}\text { M: } 26 \\
\text { F: } 42\end{array}$ & $\begin{array}{r}\text { M: } 10 \\
\text { F: } 10\end{array}$ & $x^{2}=0.9$ & 1 & vis \\
\hline $\begin{array}{l}\text { Marital } \\
\text { statusi }\end{array}$ & $\begin{array}{l}\text { Single: } 9 \\
\text { Not S: } 59\end{array}$ & $\begin{array}{c}\text { Single: } 4 \\
\text { Not S: } 16\end{array}$ & $x^{2}=0.6$ & 1 & ss \\
\hline Agch & $\begin{aligned} \mathrm{M} & =47.4 \\
\mathrm{SD} & =18.9\end{aligned}$ & $\begin{aligned} M & =41.6 \\
S D & =16.3\end{aligned}$ & $F=1.6$ & 1. 86 & NS \\
\hline Income' & $\begin{aligned} \mathrm{M} & =0.6 \\
\mathrm{SD} & =0.5\end{aligned}$ & $\begin{aligned} \mathrm{M} & =0.4 \\
\mathrm{SD} & =0.5\end{aligned}$ & $F=1, n$ & 1.86 & is \\
\hline Education' & $\begin{aligned} \mathrm{M} & =4.3 \\
\mathrm{SD} & =1.8\end{aligned}$ & $\begin{aligned} \mathrm{M} & =4.6 \\
\mathrm{SD} & =1.7\end{aligned}$ & $F=0.4$ & 1.86 & vS \\
\hline
\end{tabular}

"Chi-square test.

"Analysis of variance.

Table IV.--results of the analysis of covariance, dependent variable: PAIS-SR total score at T4; independent variables: type of treatment (stoma vs. nonstoma) and diagnosis (cancer vs. noncancer)

\begin{tabular}{lccccc}
\hline Source of variation & Sum of squares & $d f$ & Mean square & $F$ & Signif. $F$ \\
\hline Covariates & 815.98 & 2 & 407.99 & 2.96 & NS \\
$\quad$ Age & 21.06 & 1 & 21.06 & 0.15 & NS \\
$\quad$ Income & 681.66 & 1 & 681.66 & 4.94 & 0.03 \\
Main effects & 31.09 & 1 & 31.09 & 0.23 & NS \\
$\quad$ Type of treatment & 2.87 & 1 & 2.87 & 0.02 & NS \\
$\quad$ Diagnosis & 326.84 & 1 & 326.84 & 2.37 & NS \\
Two-way interactions & 1175.41 & 5 & 235.08 & 1.71 & NS \\
$\quad$ Treatment $\times$ diagnosis & 8547.58 & 62 & 137.86 & & \\
$\quad$ Explained & 9722.99 & 67 & 145.12 & & \\
$\quad$ Risidual & & & & & \\
$\quad$ Total & &
\end{tabular}


Bekkers, M.J.T.M., Knippenberg, F.C.E. van, Dulmen, A.M. van, Borne, H.W. van den, Berge Henegouwen, G.P. van. Survival and psychosocial adjustment to stoma surgery and nonstoma bowel resection: a 4-year follow-up. Journal of Psychosomatic Research: 1997, 42(3), 235-244

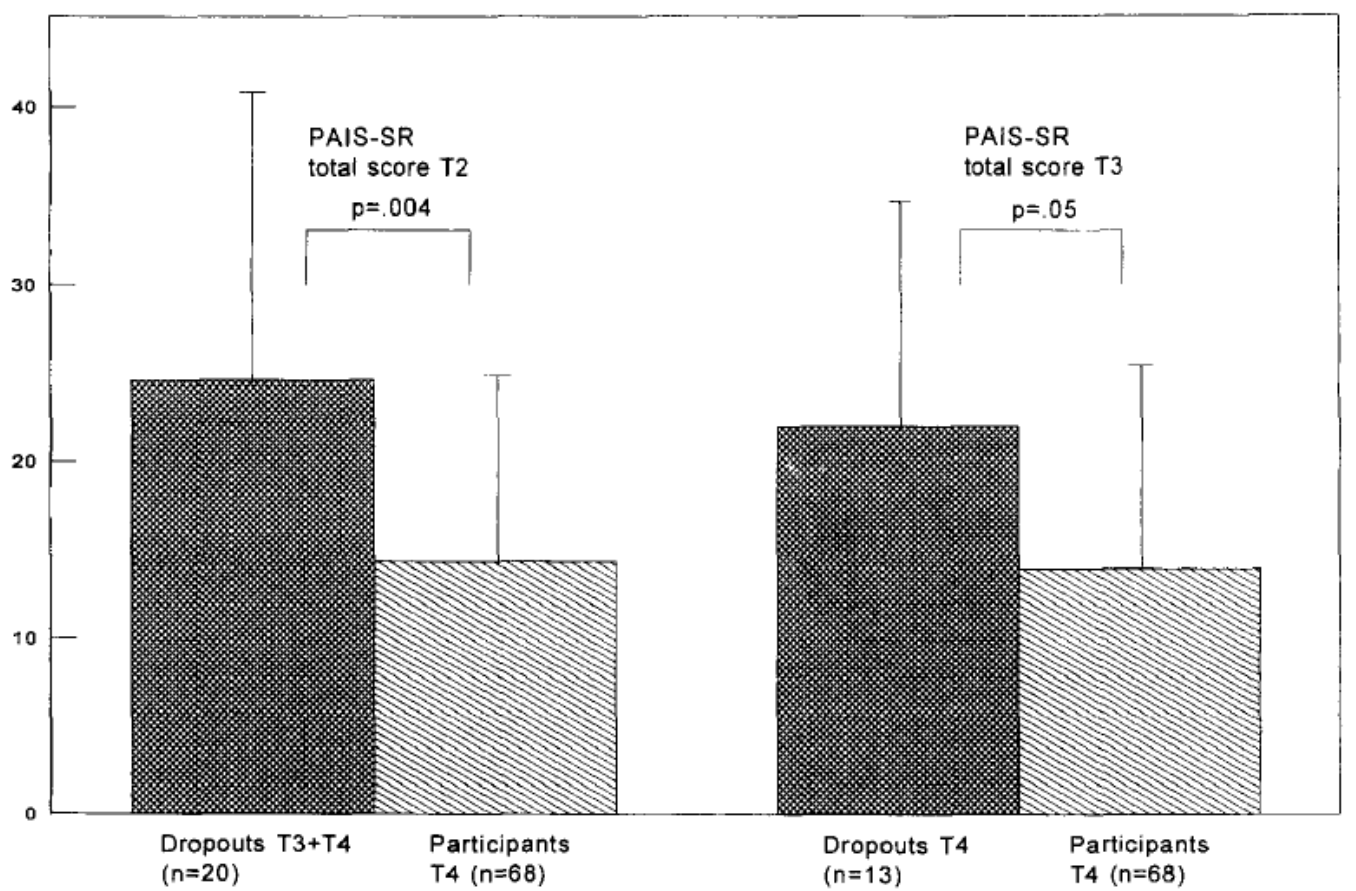

Fig. 1. The adjusted means on the early PAIS-SR total scales for the long-term participants and the patients who dropped out later on because of death or end-stage disease.

Table V.-Results of the analysis of covariance (dependent variable: PAIS-SR total score 4 months after surgery [T2]; independent variables: type of treatment [stoma vs. nonstoma] and status of participation of sotma and nonstoma patients since $T 2$ until now based on death and terminal illness (dropped out $N=20$. long-term participants $N=68$ )

\begin{tabular}{|c|c|c|c|c|c|}
\hline Source of variation & Sum of squares & $d f$ & Mean square & $F$ & Signif. of $t$ \\
\hline Covariates & 29.21 & 2 & 14.64 & 0.84 & NS \\
\hline Age & 3.35 & 1 & 3.35 & 0.02 & NS \\
\hline Income & 21.33 & 1 & 21.33 & 0.12 & NS \\
\hline Main effects & 2010.155 & 2 & 1005.03 & 6.19 & 0.003 \\
\hline Typc of treatment & 518.25 & 1 & 518.25 & 3.19 & sis \\
\hline $\begin{array}{l}\text { Status of participation } \\
\text { since } T 2\end{array}$ & 913.04 & 1 & 913.04 & 5.63 & $0,(120)$ \\
\hline \multicolumn{6}{|l|}{ Two-way interactions } \\
\hline $\begin{array}{l}\text { Treatment } \times \text { status of } \\
\text { participation }\end{array}$ & 836.82 & 1 & 836.82 & 5.16 & 0.0126 \\
\hline Explained & 2876.08 & 5 & 575.22 & 3.54 & 0,006 \\
\hline Residual & 13309.52 & 82 & 162.31 & & \\
\hline Total & 16185.59 & 87 & 186.04 & & \\
\hline
\end{tabular}

